\title{
Automatic collision avoidance of ships
}

\author{
Y Xue $^{1,2 *}$, B S Lee ${ }^{1}$, and D Han ${ }^{2}$ \\ ${ }^{1}$ Department of Naval Architecture and Marine Engineering, Universities of Glasgow and Strathclyde, Glasgow, UK \\ ${ }^{2}$ College of Shipbuilding Engineering, Harbin Engineering University, People's Republic of China
}

The manuscript was received on 23 June 2008 and was accepted after revision for publication on 27 October 2008.

DOI: 10.1243/14750902JEME123

\begin{abstract}
One of the key elements in automatic simulation of ship manoeuvring in confined waterways is route finding and collision avoidance. This paper presents a new practical method of automatic trajectory planning and collision avoidance based on an artificial potential field and speed vector. Collision prevention regulations and international navigational rules have been incorporated into the algorithm. The algorithm is fairly straightforward and simple to implement, but has been shown to be effective in finding safe paths for all ships concerned in complex situations. The method has been applied to some typical test cases and the results are very encouraging.
\end{abstract}

Keywords: collision avoidance, potential field, speed vector, manoeuvring simulator

\section{INTRODUCTION}

Owing to the steady growth of world trade the volume of international maritime transport is increasing. Today's waterways and harbours are becoming busier and vessels are becoming larger, more specialized, and faster than before. It is hardly surprising, therefore, that accidents of collision and grounding still happen frequently despite advances in modern and advanced navigational aids and equipment.

An investigation of 3000 marine accidents from 2002 to 2006 indicated that collisions accounted for about 22 per cent [1] and over 80 per cent of accidents of collision can be put down to human decision failure. One of the most effective approaches to minimizing accidents owing to human failure, and consequently enhancing the general safety level of ships, is to increase the degree of automation where appropriate to assist the decisionmaking process [2].

Another important application of automatic navigation is in time-domain simulation. With the development of information technology (IT), timedomain simulation is becoming increasingly popular

*Corresponding author: Henry Dyer Building, Research Area, 100 Montrose Street, Glasgow G4 OLZ, UK.

email: yanzhuo.xue@strath.ac.uk as a tool for design and operational planning. This tool allows the users to try out ideas and observe how the system behaves before it is constructed. Simulation of ship manoeuvring provides a costeffective method of assessing ship's handling capabilities in diverse scenarios and can be used by the local pilots and ship's master and officers for manoeuvring rehearsals, as well as in the design and development of new berth layouts and channel arrangements as part of port development [3], saving much time and resources. The most commonly used tools in this type of work are 'bridge simulators' with an actual person of harbour pilot calibre in charge of the simulated control of the ship. This approach is highly realistic and effective. However, it limits the number of runs and conditions which can be tested, owing to the difficulty in 'fast-track' simulation and associated high costs.

A much more cost-effective tool is an automatic manoeuvring simulator which does not involve a human steersman but realistically emulates his/her performance. Figure 1 shows the outline structure of the system to be simulated.

The automatic navigation element should:

(a) identify where the ship is and where it should go;

(b) detect a potential collision situation and calculate a safe path to the destination avoiding collision; 


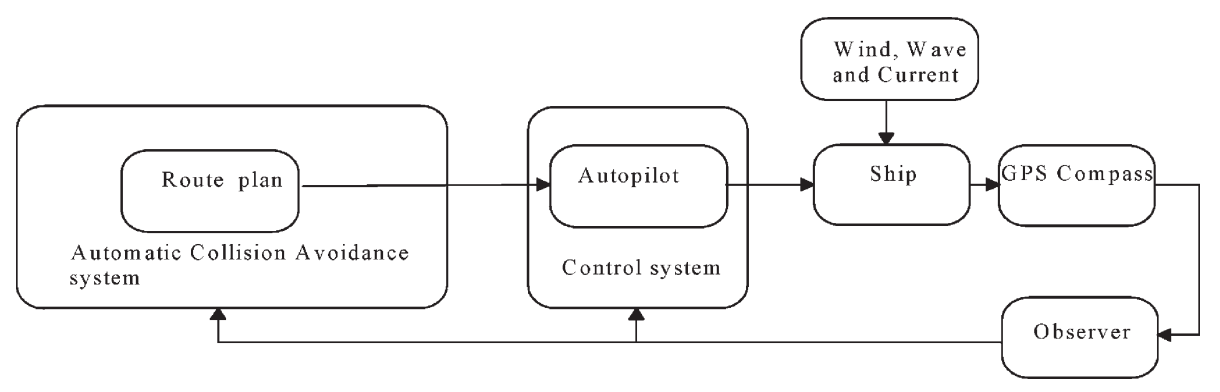

Fig. 1 The outline structure of the system

(c) control the ship automatically to follow the path thus identified.

Of course, when it is used as a tool to assist the human navigator, only the first two functions will be required. The current paper concentrates on the automatic navigation element including collision avoidance algorithm.

\section{MANOEUVRING MODEL USED}

The safety of navigation requires precise knowledge of the manoeuvring behaviour of the ship. It is well known that fully to represent a manoeuvring ship in space requires a six-degrees-of-freedom description. To simplify the problem, it is assumed that the steering of a ship can be regarded as a rigid-body motion on the horizontal plane, as is customary. Thus, the mathematical model is simplified to three degrees of freedom. With the global and ship coordinate systems shown in Fig. 2, the equations of the motion can be written as [4]

$$
\begin{aligned}
& \text { Surge } m\left(\dot{u}-v r-x_{\mathrm{G}} r^{2}\right)=X \\
& \text { Sway } m\left(\dot{v}+u r+x_{\mathrm{G}} \dot{r}\right)=Y
\end{aligned}
$$

Yaw $I_{Z} \dot{r}+m x_{\mathrm{G}}(\dot{v}+u r)=N$

where

$m$ is the mass of the ship

$u, v$ represent surge speed and sway speed respectively

$\dot{u}, \dot{v}$ represent surge and sway acceleration respectively

$r, \dot{r}$ are yaw rate and yaw acceleration

$X$ is force applied on the ship in the $x$-direction

$Y$ is force applied on the ship in the $y$-direction

$I_{Z}$ is yaw moment of inertia of the ship

$N$ is yaw moment
The force $X, Y$, and moment $N$ can be expressed as functions of the state variables $u, v, r$, their time derivatives $\dot{u}, \dot{v}, \dot{r}$, and the rudder angle $\delta$. Hence

$$
\begin{aligned}
& X=X(u, v, r, \dot{u}, \dot{v}, \dot{r}, \delta) \\
& Y=Y(u, v, r, \dot{u}, \dot{v}, \dot{r}, \delta) \\
& N=N(u, v, r, \dot{u}, \dot{v}, \dot{r}, \delta)
\end{aligned}
$$

This model of the ship that includes surge, sway, and yaw will yield sufficient information to show the manoeuvring behaviour of the ship.

In this paper, the model of Mariner class vessel was chosen for the research, because this ship has been studied in detail in various comparative studies by different authors and detailed information is available on its manoeuvring characteristics. For this ship the mathematical model which relates the yaw $(\psi)$ with the rudder angle $(\delta)$ is described by the following equations

$$
\begin{aligned}
& {\left[\begin{array}{ccc}
m^{\prime}-X_{\dot{u}}^{\prime} & 0 & 0 \\
0 & m^{\prime}-Y_{\dot{\nu}}^{\prime} & m^{\prime} x_{\mathrm{G}}^{\prime}-Y_{\dot{r}}^{\prime} \\
0 & m^{\prime} x_{\mathrm{G}}^{\prime}-N_{\dot{v}}^{\prime} & 0
\end{array}\right]\left[\begin{array}{c}
\Delta \dot{u}^{\prime} \\
\Delta \dot{\nu}^{\prime} \\
\Delta \dot{r}^{\prime}
\end{array}\right]} \\
& =\left[\begin{array}{c}
\Delta X^{\prime} \\
\Delta Y^{\prime} \\
\Delta N^{\prime}
\end{array}\right]
\end{aligned}
$$

where all variables designed with the superscript (') are normalized by Prime-System (where $L_{\mathrm{pp}}$ is the length of ship between perpendiculars, and ship's total speed $U=\sqrt{u^{2}+v^{2}}$ are normalization variables).

The rudder forces are

$$
\begin{aligned}
\Delta X_{\text {rudder }}^{\prime}= & X_{\delta \delta}^{\prime} \Delta \delta^{\prime 2}+X_{u \delta \delta}^{\prime} \Delta u^{\prime} \Delta \delta^{\prime 2} \\
& +X_{\nu \delta}^{\prime} \Delta v^{\prime} \Delta \delta^{\prime}+X_{u v \delta}^{\prime} \Delta u^{\prime} \Delta v^{\prime} \Delta \delta^{\prime}
\end{aligned}
$$




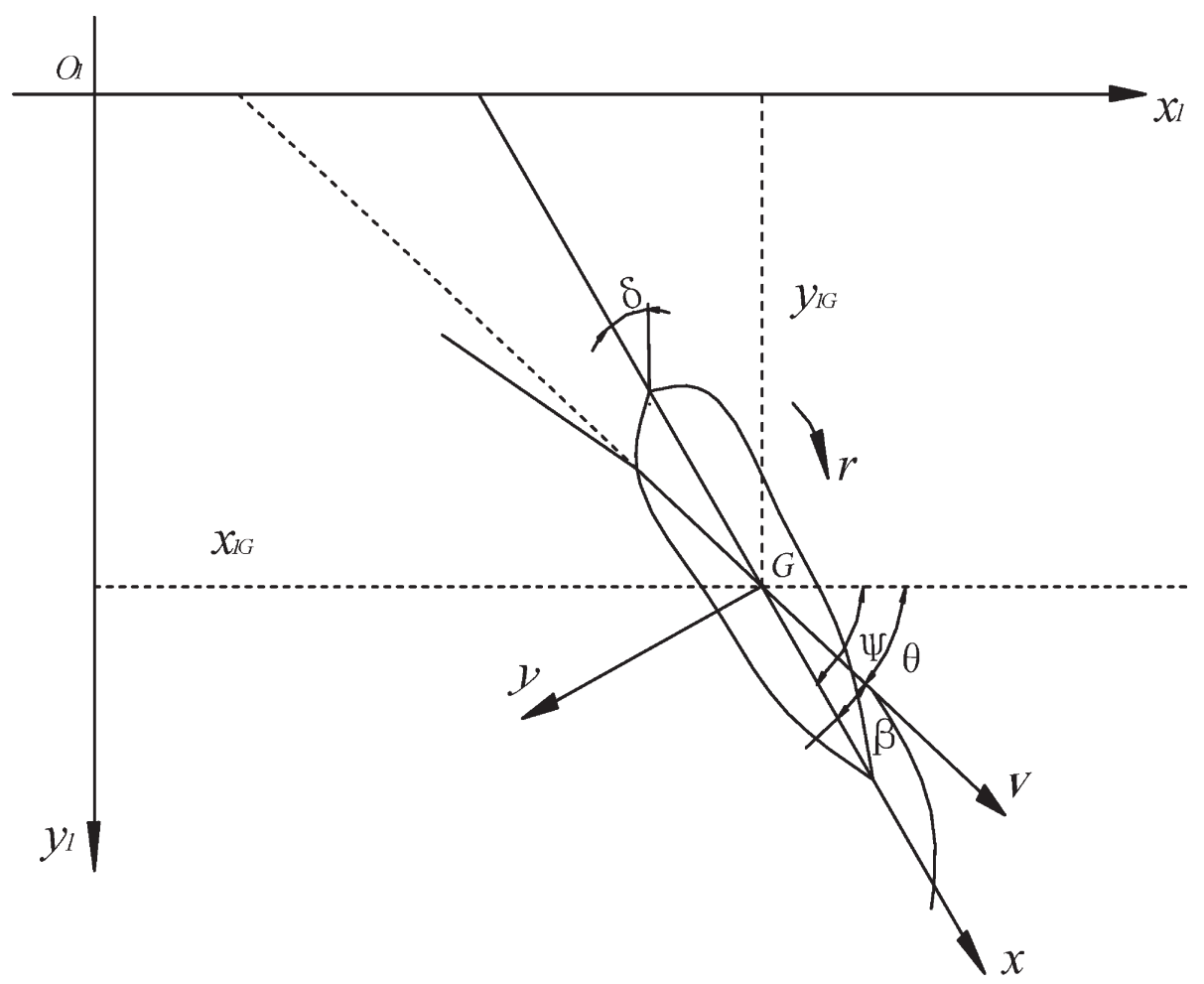

Fig. 2 Global and ship coordinate systems

$$
\begin{aligned}
\Delta Y_{\text {rudder }}^{\prime}= & Y_{\delta}^{\prime} \Delta \delta^{\prime}+Y_{\delta \delta \delta}^{\prime} \Delta \delta^{3} \\
& +Y_{u \delta}^{\prime} \Delta u^{\prime} \Delta \delta^{\prime}+Y_{u u \delta}^{\prime} \Delta u^{\prime 2} \Delta \delta^{\prime} \\
& +Y_{\nu \delta \delta}^{\prime} \Delta v^{\prime} \Delta \delta^{\prime 2}+Y_{\nu v \delta}^{\prime} \Delta v^{\prime 2} \Delta \delta^{\prime} \\
\Delta N_{\text {rudder }}^{\prime}= & N_{\delta}^{\prime} \Delta \delta^{\prime}+N_{\delta \delta \delta}^{\prime} \Delta \delta^{3} \\
& +N_{u \delta}^{\prime} \Delta u^{\prime} \Delta \delta^{\prime}+N_{u u \delta}^{\prime} \Delta u^{\prime 2} \Delta \delta^{\prime} \\
& +N_{\nu \delta \delta}^{\prime} \Delta v^{\prime} \Delta \delta^{\prime 2}+N_{v v \delta}^{\prime} \Delta v^{\prime 2} \Delta \delta^{\prime}
\end{aligned}
$$

The main data and non-dimensional coefficients of this ship model are: $m^{\prime}=798 \times 10^{-5}, I_{Z}^{\prime}=39.2 \times 10^{-5}$, $x_{G}^{\prime}=-0.023$. More coefficients can be found in reference [4].

\section{ROUTE FINDING}

Route finding in a congested waterway and harbour is a complex task because of many limitations and/ or constraints generated by ship kinematics, mechanics and manoeuvrability, hydrodynamics, and the operating environment. This is further complicated by the vessel mission, geographical constraints, existence of obstacles, requirement of collision avoidance, and feasibility [5]. Finding a safe route for a ship to follow while avoiding collision is traditionally assisted by automatic radar plotting aids (ARPA). The ARPA system can process positional data and display the navigational situation on the radar screen and allow the navigator to make reasonable decisions on what manoeuvre to take. The final decision on how to act in order to avoid the collision, however, must still be the responsibility of the navigator.

For a given circumstance (i.e. a collision situation), an intelligent route-planning method can help the navigator to make correct decisions and choose a proper manoeuvre. When a simulator equipped with such a capability is used for training purposes, it can teach him good habits and enhance his general intuition on how to behave in similar situations in the future.

Much research work on finding a safe route has been carried out with the development of computer science. Ito et al. used a genetic algorithm (GA) to design a ship route [6], while Zhao and colleagues used fuzzy [7], and Saburo Tsuruta et al. used an expert system for navigation at sea [8]. An evolutionary algorithm used for planning a safe trajectory was presented in reference [9]. These methods are associated with optimization algorithms, resulting in optimal global path planning. However useful they are for global route planning, sometimes they do not 
produce appropriate results for localized routefinding problems. Furthermore, previous research work has not effectively addressed two important problems:

(a) navigational rules, including regulations of preventing collisions at sea and general practice of seamen, are usually not taken into consideration in route planning, as these are not needed for global route planning;

(b) most of the proposed approaches consider encounters with other vessels in the open sea environment only (i.e. there is no land involved in the process of route planning) and assume that the target ships do not change their courses.

To simulate realistic situations where many vessels use confined seaways simultaneously, a new approach is therefore required.

\section{POTENTIAL FIELD METHOD FOR ROUTE FINDING}

The potential field method was first used by Khatib [10] for robot path planning in the 1980s. The basic concept of the potential field method is to fill the robot's workspace with an artificial potential field in which the robot is attracted to its goal position and repulsed away from the obstacles. This method is particularly attractive because of its mathematical elegance and simplicity. It allows real-time robot operations in a complex environment and is currently widely used for path planning of mobile robots. When this type of route planning is used at every time step, for example, in a dynamic environment, the process can be called route finding.

The ship's route finding is, in a sense, similar to the path planning of a mobile robot. A ship sails from its starting position to its destination point $\mathrm{D}$. There is an obstacle, B, in the way of a direct route between the two points. The shortest route for the ship to follow is shown by a dotted line ('desired track') in Fig. 3. However, the actual safe route will be something like that shown as the 'actual track'. This actual track can be determined by applying the potential field method.

The ship is pulled towards the point $\mathrm{D}$, therefore, the potential energy responsible for it can be called gravity potential energy. The existence of the obstacle with imaginary potential field energy can be denoted as $\boldsymbol{U}_{\text {rep. }}$. Thus

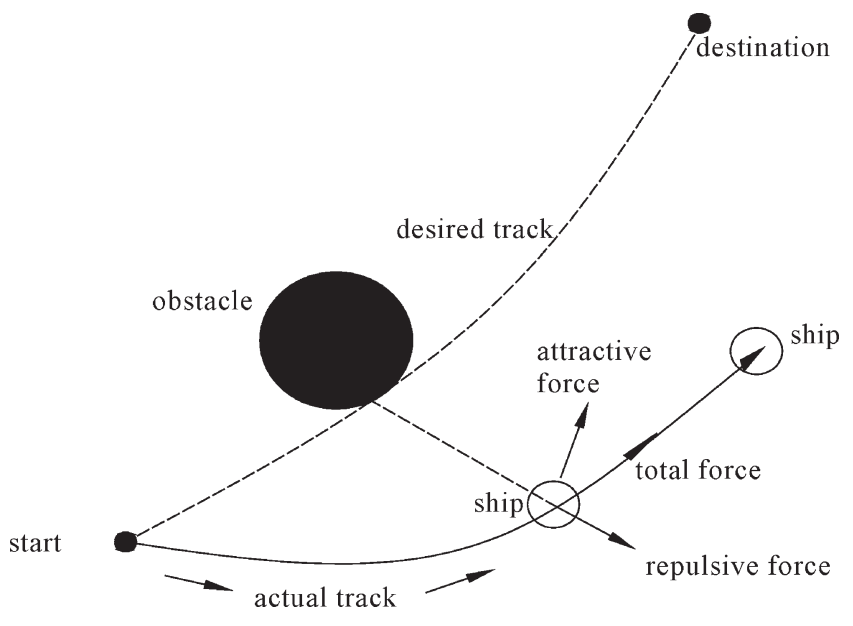

Fig. 3 The potential field in the ship's route planning

$$
\boldsymbol{U}(\boldsymbol{p})=\boldsymbol{U}_{\mathrm{att}}(\boldsymbol{p})+\boldsymbol{U}_{\mathrm{rep}}(\boldsymbol{p})
$$

where $\boldsymbol{p}$ denotes a point on the water surface, $\boldsymbol{U}_{\text {att }}$ is the potential energy owing to attraction towards destination point, and $\boldsymbol{U}_{\text {rep }}$ is the potential energy owing to repulsion of the obstacle.

The ship then is subjected to a force that is derived from this total potential force as follows

$$
\boldsymbol{F}=\boldsymbol{F}_{\text {att }}+\boldsymbol{F}_{\text {rep }}
$$

where $\quad \boldsymbol{F}_{\text {att }}=-\operatorname{grad}\left(\boldsymbol{U}_{\text {att }}(\boldsymbol{p})\right) ; \quad \boldsymbol{F}_{\text {rep }}=-\operatorname{grad}\left(\boldsymbol{U}_{\text {rep }}(\boldsymbol{p})\right)$. $\boldsymbol{F}_{\text {att }}$ may be called attractive force, and it pulls the ship towards the destination; $\boldsymbol{F}_{\text {rep }}$ is repulsive force, and it pushes the ship away from the obstacle, thus avoiding collision. The feasible path now can be found by following the direction of the total force at any given position. More than one obstacle can be accounted for by summing all the repulsive forces owing to the obstacles. Point obstacles can be simply dealt with as shown above. However, larger obstacles, such as coastlines and islands, can also be represented as a series of point obstacles judiciously placed on the boundaries.

\subsection{Attractive potential function}

The attractive potential is defined as a function of the relative distance between the ship and the destination point. In this paper, the attractive potential function is presented as follows

$$
\boldsymbol{U}_{\mathrm{att}}(\boldsymbol{p})=\alpha\left|\boldsymbol{p}_{\mathrm{d}}-\boldsymbol{P}(t)\right|^{m}
$$

where $\boldsymbol{p}_{\mathrm{d}}$ and $\boldsymbol{p}(t)$ denote the destination position and the position of ship at time $t$, respectively; 
$\left|\boldsymbol{p}_{\mathrm{d}}-\boldsymbol{p}(t)\right|$ is the Euclidean distance between the ship at time $t$ and the destination position; $\alpha$ is a scalar positive parameter; and $m$ is a positive constant. $\alpha$ and $m$ are used to adjust the magnitude of attractive potential function.

The corresponding virtual attractive force is defined as the negative gradient of the attractive potential

$$
\boldsymbol{F}_{\mathrm{att}}(\boldsymbol{p})=-\nabla \boldsymbol{U}_{\mathrm{att}}(\boldsymbol{p})=-\frac{\partial \boldsymbol{U}_{\mathrm{att}}(\boldsymbol{p})}{\partial \boldsymbol{p}}
$$

Substituting equation (13) into (14) gives

$$
\boldsymbol{F}_{\mathrm{att}}(\boldsymbol{p})=m \alpha\left|\boldsymbol{p}_{\mathrm{d}}-\boldsymbol{p}(t)\right|^{m-1}
$$

\subsection{Repulsive potential function}

To avoid the obstacles, the relative positions between the ship and the obstacles is taken into account when constructing the repulsive potential function. If the ship is within the circle of a certain radius (safe distance) measured from the obstacle in question, the repulsive force exists. Otherwise, the repulsive force is zero.

In this paper, the repulsive potential function is represented as follows

$$
\boldsymbol{U}_{\text {rep }}(\boldsymbol{p})=\left\{\begin{array}{lll}
\frac{1}{2} \eta\left|\frac{1}{p_{\mathrm{s}}}-\frac{1}{p_{\mathrm{o}}}\right|^{2}\left|\boldsymbol{p}(t)-\boldsymbol{p}_{\mathrm{d}}\right|^{n} & \text { if } & p_{\mathrm{s}} \leqslant p_{\mathrm{o}} \\
0 & \text { if } & p_{\mathrm{s}}>p_{\mathrm{o}}
\end{array}\right.
$$

In this definition, $\boldsymbol{U}_{\text {rep }}(\boldsymbol{p})$ denotes the repulsive potential generated by the obstacle; $\eta$ and $n$ are constants; $\boldsymbol{p}_{\mathrm{d}}$ and $\boldsymbol{p}(t)$ denote the destination position and the position of the ship at time $t ; p_{\mathrm{s}}$ is the distance between the ship and the obstacle, and $p_{\mathrm{o}}$ is a positive constant describing the influence range of the obstacle. $p_{\mathrm{o}}$ can be adjusted depending upon the ship, its speed, and the nature of the obstacle. A distance of 4-6 nautical miles is sometimes used for this purpose in the case of static obstacles.

Similar to the definition of the attractive force, the corresponding repulsive force is defined as the negative gradient of the repulsive potential in terms of position

$$
\boldsymbol{F}_{\text {rep }}(\boldsymbol{p})=-\nabla \boldsymbol{U}_{\text {rep }}(\boldsymbol{p})=-\frac{\partial \boldsymbol{U}_{\text {rep }}(\boldsymbol{p})}{\partial \boldsymbol{p}}
$$

Substituting equation (16) into (17) gives

$$
\boldsymbol{F}_{\text {rep }}(\boldsymbol{p})=\left\{\begin{array}{lll}
\boldsymbol{F}_{\text {rep1 }}+\boldsymbol{F}_{\text {rep2 }} & \text { if } & p_{\mathrm{s}} \leqslant p_{\mathrm{o}} \\
0 & \text { if } & p_{\mathrm{s}}>p_{\mathrm{o}}
\end{array}\right.
$$

where

$$
\begin{aligned}
& \boldsymbol{F}_{\text {rep } 1}=\eta\left(\frac{1}{p_{\mathrm{s}}}-\frac{1}{p_{\mathrm{o}}}\right) \frac{1}{p_{\mathrm{s}}^{2}}\left|\boldsymbol{p}(t)-\boldsymbol{p}_{\mathrm{d}}\right|^{n} \\
& \boldsymbol{F}_{\text {rep2 }}=\frac{n}{2} \eta\left(\frac{1}{p_{\mathrm{s}}}-\frac{1}{p_{\mathrm{o}}}\right)^{2}\left|\boldsymbol{p}(t)-\boldsymbol{p}_{\mathrm{d}}\right|^{n-1}
\end{aligned}
$$

\subsection{Total force}

After the calculation of the attractive and repulsive forces, the total virtual force can be obtained by

$$
\boldsymbol{F}_{\text {total }}(\boldsymbol{p})=\boldsymbol{F}_{\text {att }}(\boldsymbol{p})+\boldsymbol{F}_{\text {rep }}(\boldsymbol{p})
$$

where $\boldsymbol{F}_{\text {att }}(\boldsymbol{p})$ and $\boldsymbol{F}_{\text {rep }}(\boldsymbol{p})$ can be calculated through equations (15) and (18). For the case where there are multiple obstacles, the repulsive force is given by

$$
\boldsymbol{F}_{\text {rep }}(\boldsymbol{p})=\sum_{i=1}^{n_{\mathrm{obs}}} \boldsymbol{F}_{\text {rep } i}
$$

where $n_{\mathrm{obs}}$ is the number of obstacles and $\boldsymbol{F}_{\mathrm{rep} i}$ is the repulsive force generated by the $i$ th obstacle. The total virtual force $\boldsymbol{F}_{\text {total }}$ will be used for motion planning.

When using the potential field method for ship's route finding, a problem of local minima does exist under a certain condition. Consider the case shown in Fig. 4 where the ship is proceeding towards its destination and a point obstacle exists exactly in line with the destination. The repulsive force and attractive force will have opposite direction with no component at right angles to the ship's heading. No safe route can be found in this case and the algorithm breaks down. However uncommon such a situation may be, when it is detected, the ship is given a small initial deviation in its heading.

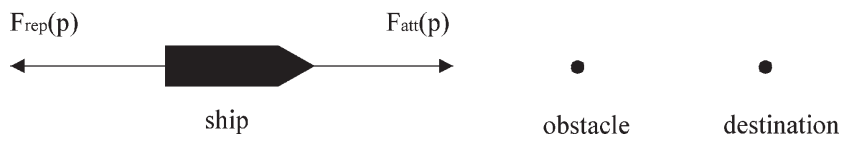

Fig. 4 Local minima problem 


\section{COLLISION AVOIDANCE}

As mentioned above, many methods of collision avoidance are associated with optimization algorithms. They can generate an optimized route between the provided waypoints. However, in some situations, such as busy channels, harbours, and so on, the number of moving obstacles in addition to static obstacles might be quite significant, substantially increasing the risk of collision. In such cases it may not be possible to designate waypoints in advance, or adhere to them rigidly when they are designated. Therefore, the objective of this study is not to solve an optimization problem for a predefined set of waypoints, but to achieve collision avoidance in real time.

All the ships within the scope of simulation will be steaming to their own destination points, while making sure that they do not collide with any obstacles. In this sense static obstacles are treated as a special case of general obstacles with zero velocity. For ships at sea, navigational rules, such as collision regulations (International Regulations for Preventing Collisions at Sea (COLREGS)) will also have to be obeyed. In this section, a method of avoiding obstacles, either moving or static, is presented.

\subsection{Determination of possible collision}

COLREGS defines the rules for navigation and collision avoidance. These rules are essential for collision avoidance and referenced throughout this paper. Further details concerning these rules and others can be found in reference [11].

According to COLREGS, the navigator has to decide whether a risk of collision exists and what manoeuvre to take to avoid collision. An automatic collision avoidance system has to decide by itself whether such a risk exists. Because there are no clear criteria for determining when the risk of collision is high enough to cause concern, a collision detection algorithm has to be formalized. For this some parameters need to be defined.

1. Safe passing distance. In this paper, safe passing distance $C_{\mathrm{S}}$ is used to define navigational boundaries. It is the smallest possible distance between two passing vessels (measured between the centre points amidships), which must be maintained for safe passage, defined here as

$$
C_{\mathrm{A}}=f \times C_{\mathrm{S}}+C_{\mathrm{E}}
$$

where $C_{\mathrm{S}}=L_{\mathrm{OW}}+L_{\mathrm{TA}}, L_{\mathrm{OW}}$ and $L_{\mathrm{TA}}$ are the length of own ship and target ship respectively and $C_{\mathrm{E}}$ is the position evaluation error. Different values for $f$ may be adopted depending on the situation [12].

2. Range of checking collision. According to COLREGS 17, there are four stages for ships in threat of collision [12] as follows:

(a) at long range, before risk of collision exists, both vessels are free to take any preventive action;

(b) when risk of collision first begins to apply the give-way vessel is required to take early and substantial action to achieve a safe passing distance and the other vessel must keep course and speed;

(c) when it becomes apparent that the give-way vessel is not taking appropriate action in compliance with the rules, the stand-on vessel is permitted to take action to avoid collision by its manoeuvre alone;

(d) when collision cannot be avoided by the giveway vessel alone, the stand-on vessel is required to act as best it can to avoid collision.

As mentioned before, in some situations, a number of ships may be in the vicinity of the vessel. However, not all of them may be in a situation with potential collision with the vessel. Therefore, an important issue in collision avoidance is to determine under what circumstances the risk of collision needs to be evaluated. It is reasonable to assume that the most crucial factor determining this will be the distance between the two ships. In this paper, the distance at which collision risk begins to be assessed is termed collision checking range $C_{\mathrm{R}}$. The magnitude of $C_{\mathrm{R}}$ depends on weather condition, sailing area, and the speed of the own ship. Because navigators are expected to take their time before making their decision, usually 3 to $6 \mathrm{~min}$, this decision time is also considered in the collision checking range $C_{\mathrm{R}}$.

\subsection{Determination of encounter type}

If the target ship is within the collision checking range, an encounter exists. COLREGS defines three basic encounter types, as shown in Fig. 5.

The specification of the encounter type is given by Table 1. The parameters used in the classification are relative course angle between the own ship and target $\operatorname{ship} \psi_{\mathrm{R}}=\psi_{\mathrm{OS}}-\psi_{\mathrm{TS}}$ and the navigation speeds of own ship and target ship, $V_{\mathrm{OS}}$ and $V_{\mathrm{TS}}$ respectively [13]. 


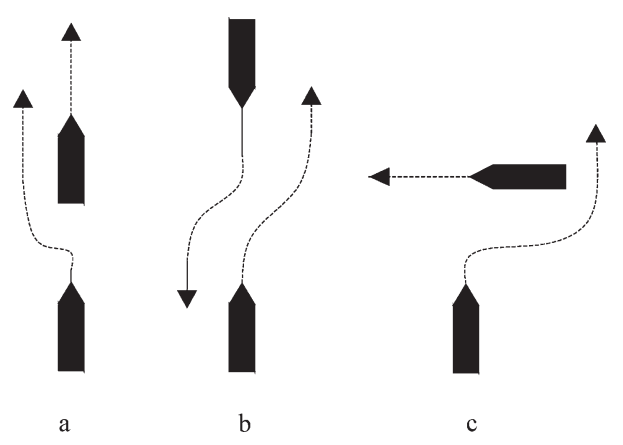

Fig. 5 Ship encounter type of (a) overtaking, (b) heading-on, and (c) crossing

\subsection{Strategy of collision avoidance}

As described previously in section 4 , the potential field method has been found very effective at avoiding stationary obstacles. However, the situation becomes a little more complex when the obstacle is moving, as for example, when two ships are sailing towards the same point at the same time.

When two ships experience an 'encounter situation', COLREGS states that one ship should maintain course and speed (stand-on vessel), while the other is responsible for the avoidance manoeuvre (giveway vessel) (COLREGS 16 and 17) (see Fig. 6).

The reasoning behind assigning one vessel to stand-on while the other is to give-way is to minimize the possibility of uncoordinated ship manoeuvres. The avoiding manoeuvres to be taken, therefore, should be in accordance with the regulations to which all maritime traffic adhere.

Figure 7 shows the relationship between vectors used in the strategy of avoiding collision of two ships. In this figure, the magnitude of vector $\boldsymbol{P}_{\mathrm{OT}}$ is the distance between own ship and target ship at time $t$. $\boldsymbol{P}_{\mathrm{OT}}=\boldsymbol{P}_{\mathrm{T}}-\boldsymbol{P}_{\mathrm{O}}$, where $\boldsymbol{P}_{\mathrm{T}}$ and $\boldsymbol{P}_{\mathrm{O}}$ are position vectors of the target ship and own ship. Vector $\boldsymbol{V}_{\mathrm{OT}}$ is the relative speed of the own ship with respect to the target ship. $\boldsymbol{V}_{\mathrm{OT}}=\boldsymbol{V}_{\mathrm{O}}-\boldsymbol{V}_{\mathrm{T}}$, where vector $\boldsymbol{V}_{\mathrm{O}}$ and vector $\boldsymbol{V}_{\mathrm{T}}$ denote the velocity of own ship and target ship at time $t$, respectively.

It can easily be seen that the risk of collision exists if the extension of the relative velocity $\boldsymbol{V}_{\text {От }}$ of the two

Table 1 Specification of encounter type

\begin{tabular}{ll}
\hline Encounter type & Criteria \\
\hline Heading-on & $\left|\psi_{\mathrm{R}}\right| \geqslant 168.75^{\circ}$ \\
Target ship being overtaken & $\left|\psi_{\mathrm{R}}\right|<11.25^{\circ}$ and $V_{\mathrm{Os}}>V_{\mathrm{TS}}$ \\
Target ship overtaking & $\left|\psi_{\mathrm{R}}\right|<11.25^{\circ}$ and $V_{\mathrm{Os}}<V_{\mathrm{TS}}$ \\
$\begin{array}{l}\text { Target crossing starboard- } \\
\quad \text { to-port }\end{array}$ & $-168.75^{\circ}<\psi_{\mathrm{R}}<-11.25^{\circ}$ \\
$\begin{array}{l}\text { Target crossing port-to- } \\
\quad \text { starboard }\end{array}$ & $11.25^{\circ}<\psi_{\mathrm{R}}<168.75^{\circ}$ \\
\hline
\end{tabular}

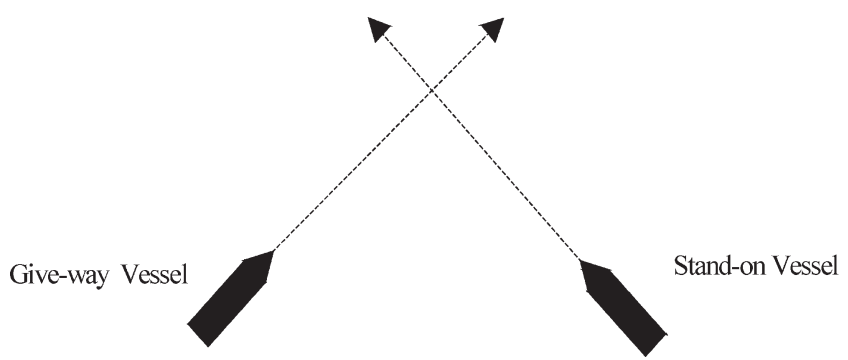

Fig. 6 The give-way vessel yields to the stand-on vessel

ships crosses a circle of radius $C_{\mathrm{A}}$ around the target. This condition can be formalized as $a<b$, where the angles $a$ and $b$ are defined graphically in Fig. 7 .

The strategy for collision detection, therefore, is reduced to checking angles $a$ and $b$ at each time step. If $a<b$, the situation can be rectified by changing the velocity of either or both ships. In reality this means changing the speed and/or heading of either or both ships. It has been known that ship masters do not like changing speed as the primary means of navigation unless it is unavoidable. Thus, it is more likely that applying heading angles is to be used as the primary means of avoiding collision in normal circumstances. This is the strategy used for finding a safe route in this paper, but for emergencies where collision cannot be avoided by changing heading alone, the method of reducing speed will be considered. However, such emergencies only occur when appropriate preventive action is not taken well in advance.

When there are more than two ships involved in relative proximity, the situation can become much more complicated. The automatic simulation program has to find a safe route not only for the 'own' ship but for all the ships concerned. In other words, the program has to consider each moving ship in turn as the 'own' ship. The algorithm adopted for this purpose can be described as follows:

(a) at each time step the system examines each ship in turn to see if it is within the collision checking range and with which ship(s);

(b) if the ship is within the checking range with one or more ships as targets, then the collision detection procedure described above is applied for each target;

(c) if there are more than one target, the target which is in the most imminent danger is given the priority and avoidance action is taken for this target;

(d) this process is repeated throughout the entire simulation while the ship is in motion. 


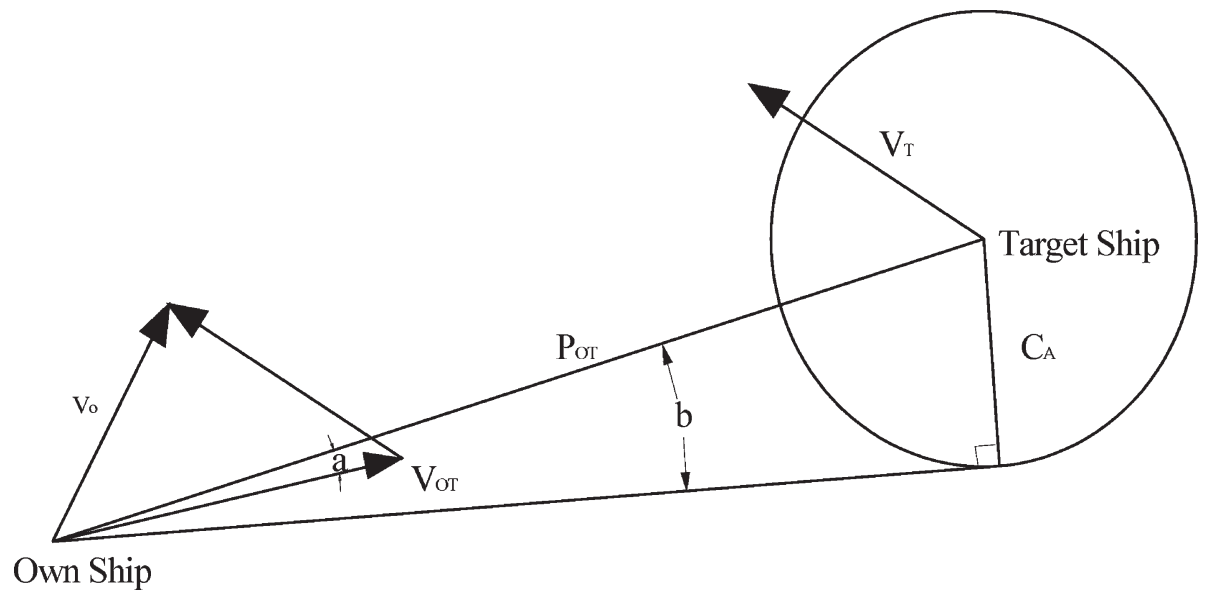

Fig. 7 The basic strategy of two ships avoiding each other

As is most likely, there will be static obstacles to avoid as well, and in that case, the ships which have to avoid static obstacles will be given a higher priority to manoeuvre.

\section{DYNAMIC ROUTE GENERATION AND HEADING CONTROL}

The aim of this research is to simulate the ship manoeuvring in real time. The ship dynamics should not be ignored. So the next work is to check whether the manoeuvring requirement thus found can be followed by the ship.

The environment where the ship sails is changed, so the system does not generate the whole route initially, but only generates the part of the route closest to the current position. At the next time step this manoeuvring requirement may have to be altered owing to changing circumstances and difficulty in implementing the manoeuvre. This procedure can thus be called 'dynamic route generation'. The ship states updated at every time step are input into the automatic collision system to calculate the desired route immediately in front of the ship in the form of waypoints. This can be translated into a heading requirement. The command is analogous to a rudder command that would be issued by heading autopilot. Thus the system can automatically control ship to sail to destination.

\subsection{Cubic spline algorithm for route generation}

It is common practice to represent the desired route using straight lines and circular arcs to connect the waypoints. But the drawback of this method is that discontinuities in the desired yaw rate $r_{\mathrm{d}}$ can occur.
Such discontinuities require infinite forces in the actuators and are important to avoid [14].

In the present paper, the cubic spline method for generation of continuous routes connecting some dynamic waypoints found in the immediate forward vicinity of the ship is presented. Using this method, the drawback as mentioned above can be avoided and every sub-route can be described by the thirdorder polynomials [5]

$$
\begin{aligned}
& x_{\mathrm{d}}(\theta)=a_{3} \theta^{3}+a_{2} \theta^{2}+a_{1} \theta+a_{0} \\
& y_{\mathrm{d}}(\theta)=b_{3} \theta^{3}+b_{2} \theta^{2}+b_{1} \theta+b_{0}
\end{aligned}
$$

where $\left(x_{\mathrm{d}}(\theta), y_{\mathrm{d}}(\theta)\right)$ denotes the position of the vessel, and where $\theta$ is the parametric variable given by

$$
\dot{\theta}=f(\theta, t)
$$

In the methods presented here, $\theta$ starts at 0 and is increased to 1 along every sub-route. Therefore, $\theta_{1}$ corresponds to waypoint $2, \theta_{2}$ corresponds to waypoint 3 , and so on. The final waypoint is when $\theta=\theta_{n-1}$.

The partial derivatives of the route with respect to $\theta$ are

$$
\begin{aligned}
& x_{\mathrm{d}}^{\theta}(\theta)=3 a_{3} \theta^{2}+2 a_{2} \theta+a_{1} \\
& y_{\mathrm{d}}^{\theta}(\theta)=3 b_{3} \theta^{2}+2 b_{2} \theta+b_{1}
\end{aligned}
$$

$x_{\mathrm{d}}^{\theta^{2}}(\theta)=6 a_{3} \theta+2 a_{2}$

$$
y_{\mathrm{d}}^{\theta^{2}}(\theta)=6 b_{3} \theta+2 b_{2}
$$


The path through the desired waypoints $\left(x_{k-1}, y_{k-1}\right)$ and $\left(x_{k}, y_{k}\right)$ must satisfy

$$
\begin{aligned}
& x_{\mathrm{d}}\left(\theta_{k-1}\right)=x_{k-1}, \quad x_{\mathrm{d}}\left(\theta_{k}\right)=x_{k} \\
& y_{\mathrm{d}}\left(\theta_{k-1}\right)=y_{k-1}, \quad y_{\mathrm{d}}\left(\theta_{k}\right)=y_{k}
\end{aligned}
$$

where $k=1, \ldots, n$. In addition, smoothness is obtained by requiring that

$$
\begin{aligned}
& \lim _{\theta \rightarrow \theta_{k}^{-}} x_{\mathrm{d}}^{\theta}\left(\theta_{k}\right)=\lim _{\theta \rightarrow \theta_{k}^{+}} x_{\mathrm{d}}^{\theta}\left(\theta_{k}\right) \\
& \lim _{\theta \rightarrow \theta_{k}^{-}} x_{\mathrm{d}}^{\theta^{2}}\left(\theta_{k}\right)=\lim _{\theta \rightarrow \theta_{k}^{+}} x_{\mathrm{d}}^{\theta^{2}}\left(\theta_{k}\right)
\end{aligned}
$$

For this problem, it is possible to add only two boundary conditions for the $x$ - and $y$-equations, respectively. Moreover

$$
\begin{aligned}
& x_{\mathrm{d}}^{\theta}\left(\theta_{0}\right)=x_{0}^{\theta}, \quad x_{\mathrm{d}}^{\theta}\left(\theta_{n}\right)=x_{n}^{\theta} \\
& y_{\mathrm{d}}^{\theta}\left(\theta_{0}\right)=y_{0}^{\theta}, \quad y_{\mathrm{d}}^{\theta}\left(\theta_{n}\right)=y_{n}^{\theta}
\end{aligned}
$$

The polynomial $x_{\mathrm{d}}\left(\theta_{k}\right)$ is given by the parameters $\alpha_{k}=\left[a_{3 k}, a_{2 k}, a_{k}, a_{0}\right]^{T}$, resulting in $4(n-1)$ unknown parameters. The number of constraints is also $4(n-1)$ if only velocity or acceleration constraints are chosen at the end points. The unknown parameters for $n$ waypoints are collected into a vector

$$
x=\left[\alpha_{k}^{T}, \ldots, \alpha_{n-1}^{T}\right]^{T}
$$

Hence, the cubic spline problem can be written as a linear equation

$$
y=\mathbf{A}\left(\theta_{k-1}, \ldots, \theta_{k}\right) x, \quad k=1,2, \ldots, n
$$

where

$$
y=\left[x_{\text {start }}, x_{0}, x_{1}, x_{1}, 0,0, x_{2}, x_{2}, 0,0, \ldots, x_{n}, x_{\text {final }}\right]^{T}(38)
$$

and $\mathbf{A}$ is a matrix containing start and end point constraints, which can be specified in terms of velocity or acceleration constraints.

\subsection{Desired heading along the route}

After calculating the desired route through the waypoints, the system can obtain the desired heading $\psi_{\mathrm{d}}(\theta)$ along the route at any given point, by calculating the direction of the tangential vector at that point

$$
\psi_{\mathrm{d}}(\theta)=\arctan \left(\frac{y_{\mathrm{d}}^{\theta}(\theta)}{x_{\mathrm{d}}^{\theta}(\theta)}\right)
$$

Then the desired yaw rate $r_{\mathrm{d}}$ is

$$
r_{\mathrm{d}}=\psi_{\mathrm{d}}^{\theta}(\theta)=\frac{x_{\mathrm{d}}^{\theta}(\theta) y_{\mathrm{d}}^{\theta^{2}}(\theta)-x_{\mathrm{d}}^{\theta^{2}}(\theta) y_{\mathrm{d}}^{\theta}(\theta)}{x_{\mathrm{d}}^{\theta}(\theta)^{2}+y_{\mathrm{d}}^{\theta}(\theta)^{2}}
$$

\subsection{PID heading controller}

Having computed the viable route with its waypoints and desired heading angle at any given point in real time, the ship has to be steered to achieve this. For this purpose an automatic pilot based on a proportional-integral-derivative (PID) control system is incorporated in the simulation.

The PID controller can be designed as follows [5]

$$
\tau_{\mathrm{N}}(s)=\tau_{\mathrm{PID}}(s)=-K_{\mathrm{p}}\left(1+T_{\mathrm{d}} s+\frac{1}{T_{\mathrm{i}}}\right) \tilde{\psi}(s)
$$

where $\tau_{\mathrm{N}}$ is the controller yaw moment; $\tilde{\psi}=\psi-\psi_{\mathrm{d}}$ is the heading error; $K_{\mathrm{p}}$ is the proportional gain constant; $T_{\mathrm{d}}$ is the derivative time constant; and $T_{\mathrm{i}}$ is the integral time constant.

A continuous-time representation of the controller is

$$
\tau_{\mathrm{PID}}(t)=-K_{\mathrm{p}} \tilde{\psi}-K_{\mathrm{d}} \tilde{r}-K_{\mathrm{i}} \int_{0}^{t} \tilde{\psi}(\tau) \mathrm{d} \tau
$$

where $\tilde{r}=r-r_{\mathrm{d}}, K_{\mathrm{d}}=K_{\mathrm{p}} T_{\mathrm{d}}$, and $K_{\mathrm{i}}=K_{\mathrm{p}} / T_{\mathrm{i}}$.

The controller gains can be found by pole placement in terms of the design parameters $\omega_{\mathrm{n}}$ and $\xi$, through

$$
\begin{aligned}
& K_{\mathrm{P}}=\frac{\omega_{\mathrm{n}}^{2} T}{K}>0 \\
& K_{\mathrm{d}}=\frac{2 \xi \omega_{\mathrm{n}} T-1}{K}>0 \\
& K_{\mathrm{i}}=\frac{\omega_{\mathrm{n}}^{3} T}{10 K}>0
\end{aligned}
$$

where $\omega_{\mathrm{n}}$ is the natural frequency and $\xi$ is the relative damping ratio, $T$ and $K$ are Nomoto time and gain constants, respectively. 


\section{EXAMPLE SIMULATION RESULTS}

To demonstrate the effectiveness of the method developed, some simulation studies were carried out. For the sake of simplicity all the moving ships within the simulation range were also assumed to be Mariner class in these studies. The parameters of simulation are given as follows: $m=2, \alpha=20$, $\eta=500, n=2, p_{\mathrm{o}}=4$ (n mile), $f=5, C_{E}=0.3$ (n mile), $K=0.185, T=107.3, \omega_{\mathrm{n}}=0.06$, and $\xi=1$.

\subsection{Stationary obstacle avoidance}

In this example, the own ship's speed is $18 \mathrm{kn}$ and starting point is at $\left(x_{\mathrm{s}}, y_{\mathrm{s}}\right)=(0,0)$ and the destination point is at $\left(x_{\mathrm{d}}, y_{\mathrm{d}}\right)=(50,45)(\mathrm{km})$. The coastlines of the channel are represented by eight discrete point obstacles placed at the following positions: $\left(x_{1}, y_{1}\right)=(3,10),\left(x_{2}, y_{2}\right)=(15,5),\left(x_{3}, y_{3}\right)=(10,20)$, $\left(x_{4}, y_{4}\right)=(25,30),\left(x_{5}, y_{5}\right)=(25,15),\left(x_{6}, y_{6}\right)=(35,40)$, $\left(x_{7}, y_{7}\right)=(40,28)$, and $\left(x_{8}, y_{8}\right)=(50,40)$.

The safe route for the ship calculated using the algorithm described above is shown in Fig. 8 and the key manoeuvring parameters are shown against time in Fig. 9.

\subsection{Collision avoidance between two ships}

\subsubsection{Two ships crossing}

The situation where the paths of two ships are likely to cross is simulated primarily to check the compliance with COLREGS. The positions and speeds of ships are given by Table 2 .

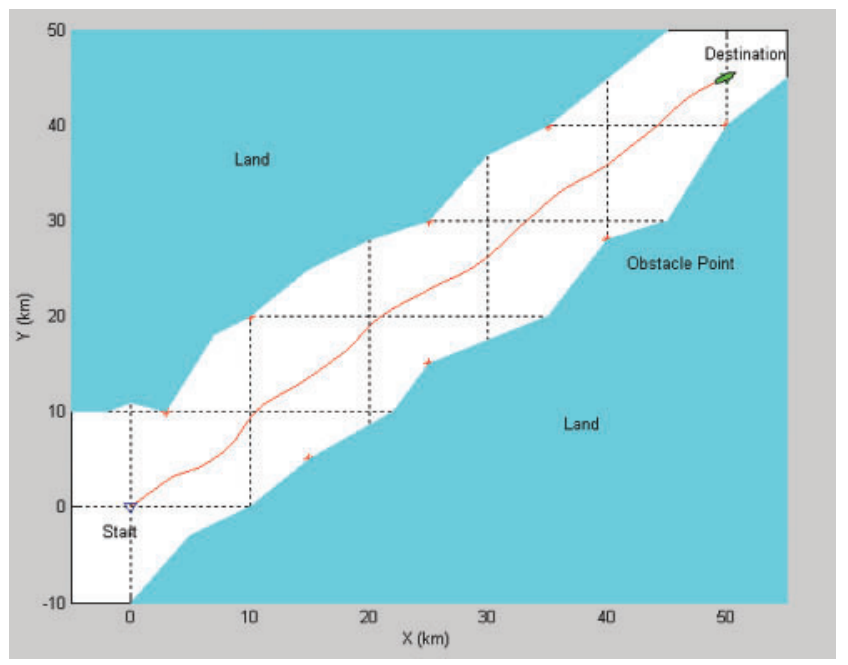

Fig. 8 A safe route obtained from the simulation

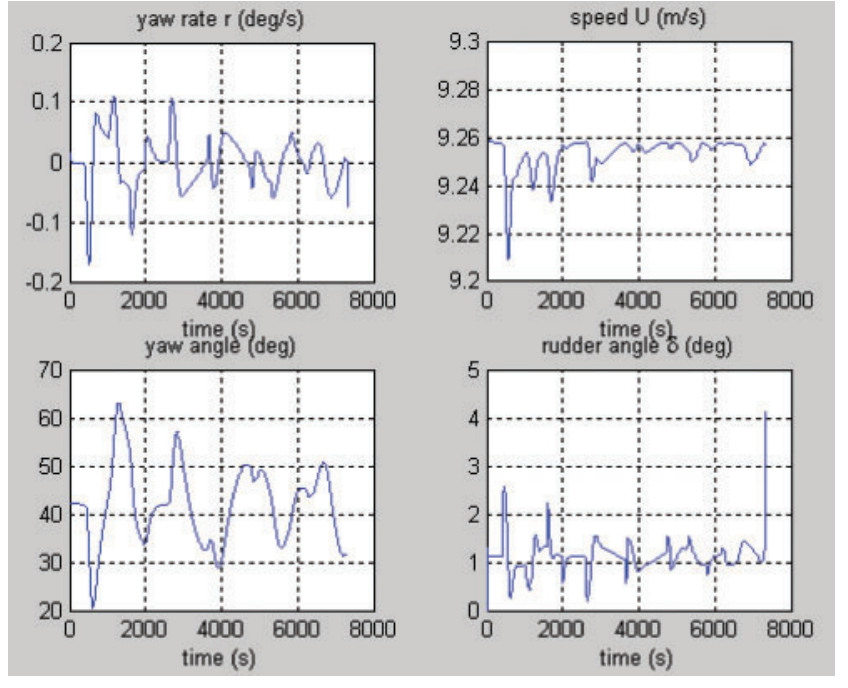

Fig. 9 Ship's yaw rate, yaw angle, speed, and rudder angle

As shown in Fig. 10, the program decides that there is a risk of collision and identifies the ship on the left ('own' ship) as the give-way ship according to COLREGS. It then manoeuvres to starboard to avoid collision, and the stand-on ship on the right ('target' ship) maintains its course and speed. As shown in Fig. 11, the two ships pass by safely. The yaw rate, yaw angle, speed, and rudder angle of the own ship from the start to the arrival at destination are given in Fig. 12.

\subsubsection{Two ships head on}

The position and speed of ships are given in Table 3. In this case both the own ship and target ship turn to starboard according to the rule. The simulation result is given in Fig. 13.

\subsubsection{One ship overtaking another}

The position and speed of the ships are given in Table 4. Because the own ship is faster than the target ship, the own ship is to turn to port to overtake the target ship in accordance with the rule. The result is presented in Fig. 14.

\subsection{Collision avoidance with multiple ships}

A complex encounter situation involving four ships was simulated in this test. The positions and speeds of all the ships concerned are given in Table 5 . The four ships are heading to an area where they are likely to head for an encounter situation. Once the 
Table 2 The positions and speeds of ships

\begin{tabular}{llll}
\hline & Start $(\mathrm{km})$ & Destination $(\mathrm{km})$ & Speed (knots) \\
\hline Own ship & $(0,0)$ & $(20,20)$ & 15 \\
Target ship 1 & $(20,0)$ & $(0,20)$ & 15 \\
\hline
\end{tabular}

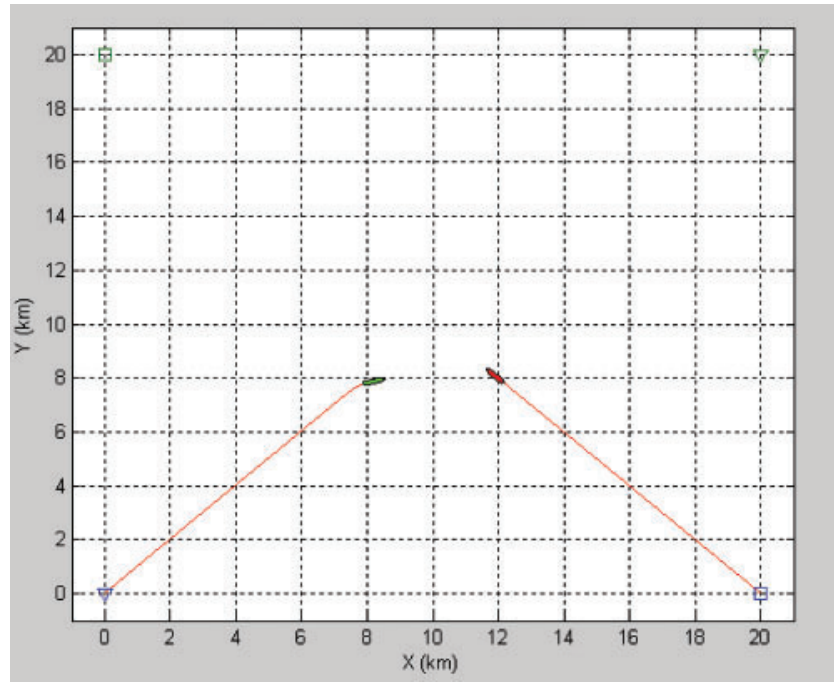

Fig. 10 Checking the collision risk

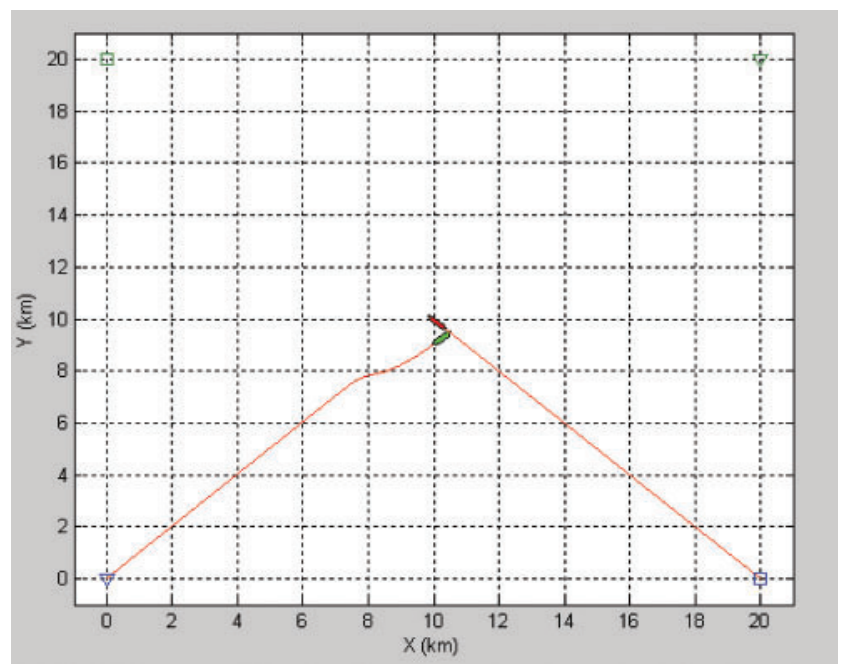

Fig. 11 Avoiding the collision

program detects the risk of collision, it attempts to identify which ship should be given the priority to avoid collision. In Fig. 16, two target ships begin to manoeuvre to avoid collision.

Two target ships were successful in avoiding collision, and then the own ship begins to turn to starboard to avoid the target ship approaching on the starboard as can be seen in Fig. 17. This simulation demonstrates that the system based on the method developed can intelligently find the safe way and

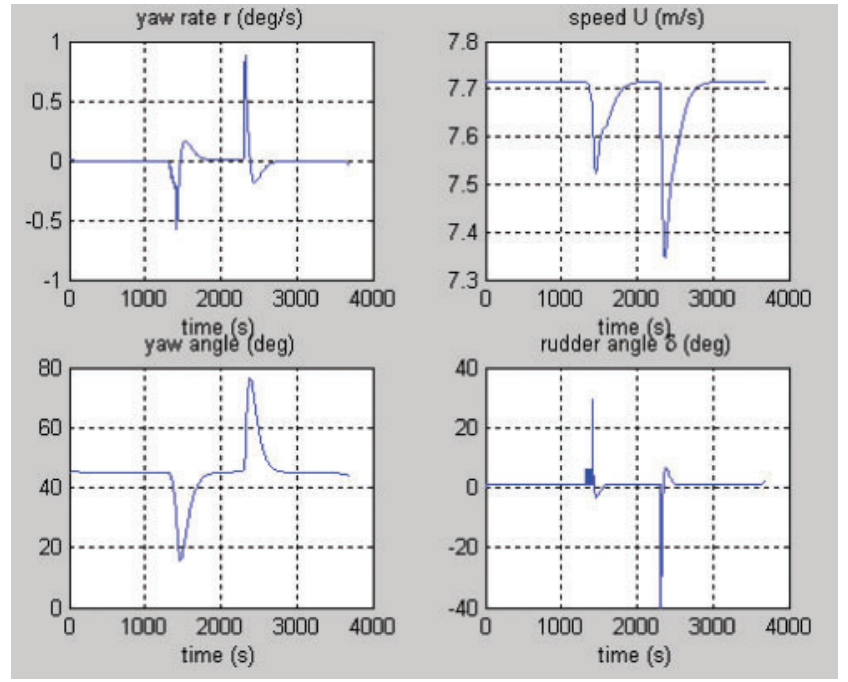

Fig. 12 Own ship's yaw rate, yaw angle, speed, and rudder angle

Table 3 The positions and speeds of ships

\begin{tabular}{llll}
\hline & Start $(\mathrm{km})$ & Destination $(\mathrm{km})$ & Speed (knots) \\
\hline Own ship & $(11,2)$ & $(11,18)$ & 15 \\
Target ship & $(10,18)$ & $(10,2)$ & 15 \\
\hline
\end{tabular}

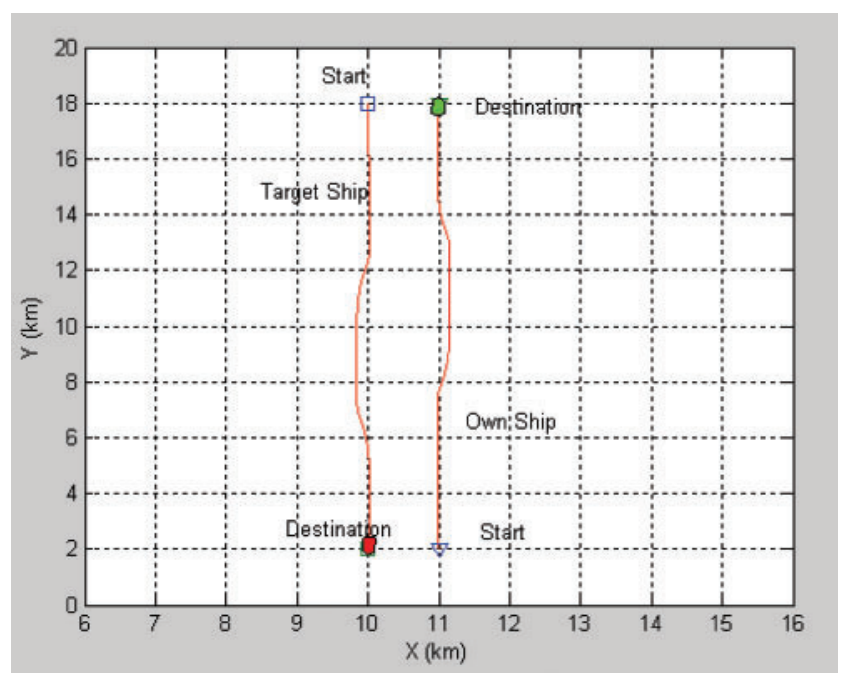

Fig. 13 Two ships head on

Table 4 The positions and speeds of ships

\begin{tabular}{llll}
\hline & Start $(\mathrm{km})$ & Destination $(\mathrm{km})$ & Speed (knots) \\
\hline Own ship & $(10,-3)$ & $(10,18)$ & 18 \\
Target ship 1 & $(11,4)$ & $(11,14)$ & 10 \\
\hline
\end{tabular}

take proper action for all the ships involved thereby avoiding collision. 


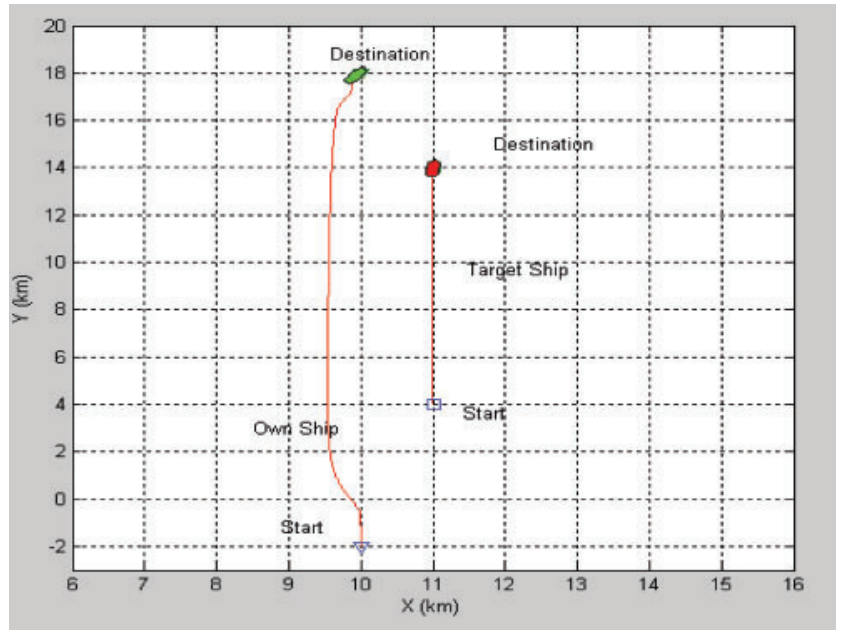

Fig. 14 One ship overtaking another

Table 5 The positions and speeds of ships

\begin{tabular}{llll}
\hline & Start $(\mathrm{km})$ & Destination $(\mathrm{km})$ & Speed $(\mathrm{knots})$ \\
\hline Own ship & $(0,0)$ & $(45,40)$ & 17 \\
Target ship 1 & $(40,0)$ & $(3,40)$ & 16 \\
Target ship 2 & $(45,30)$ & $(3,20)$ & 16 \\
Target ship 3 & $(0,30)$ & $(45,20)$ & 16 \\
\hline
\end{tabular}

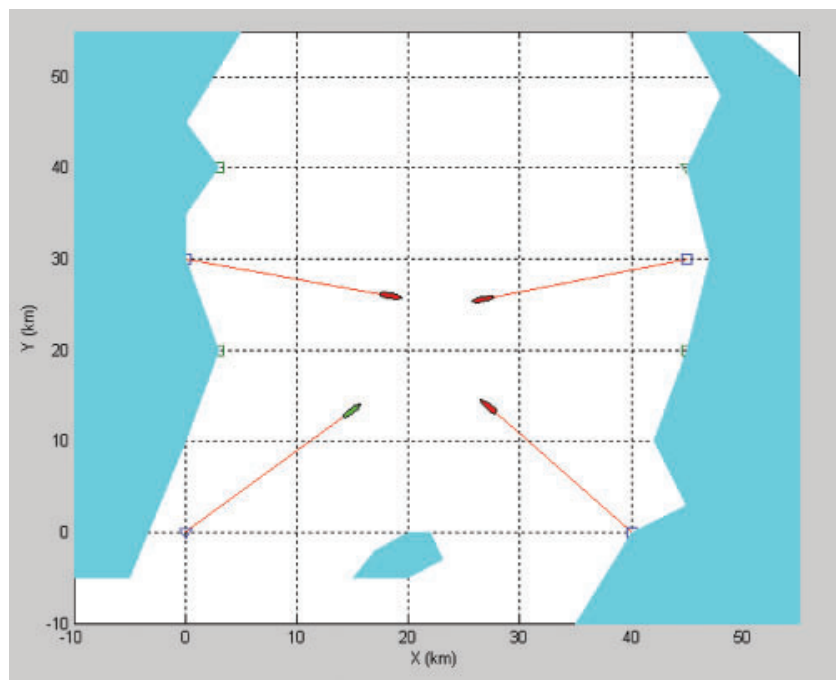

Fig. 15 Four ships meeting

\section{CONCLUDING REMARKS}

This paper has presented a method developed for finding safe passage for ships in potential collision situations to be used in an automatic simulation tool. It has been shown that the method can also be used for a decision-aid tool for navigators in control of a ship. So far as can be ascertained through the case studies, the method works well.

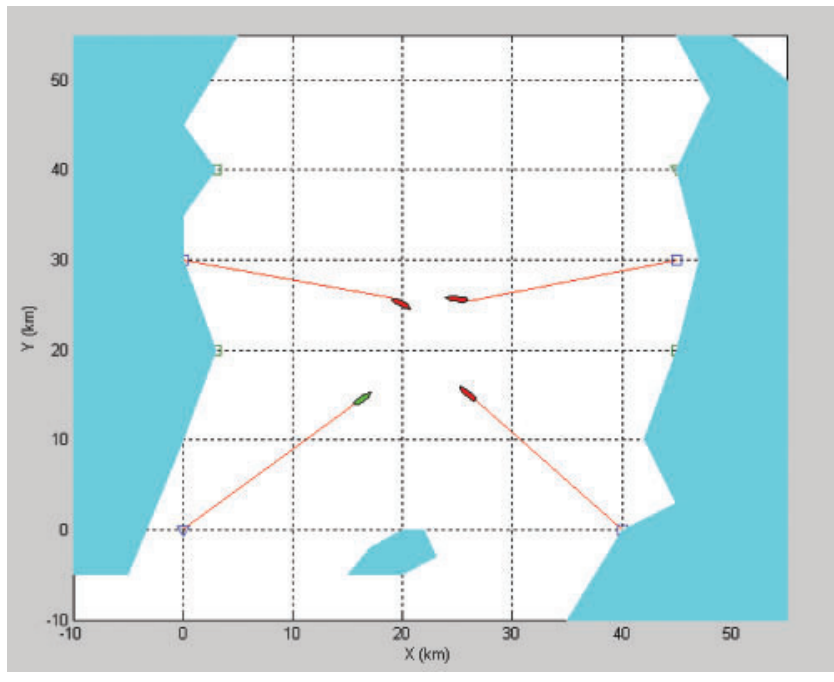

Fig. 16 Two target ships begin to manoeuvre

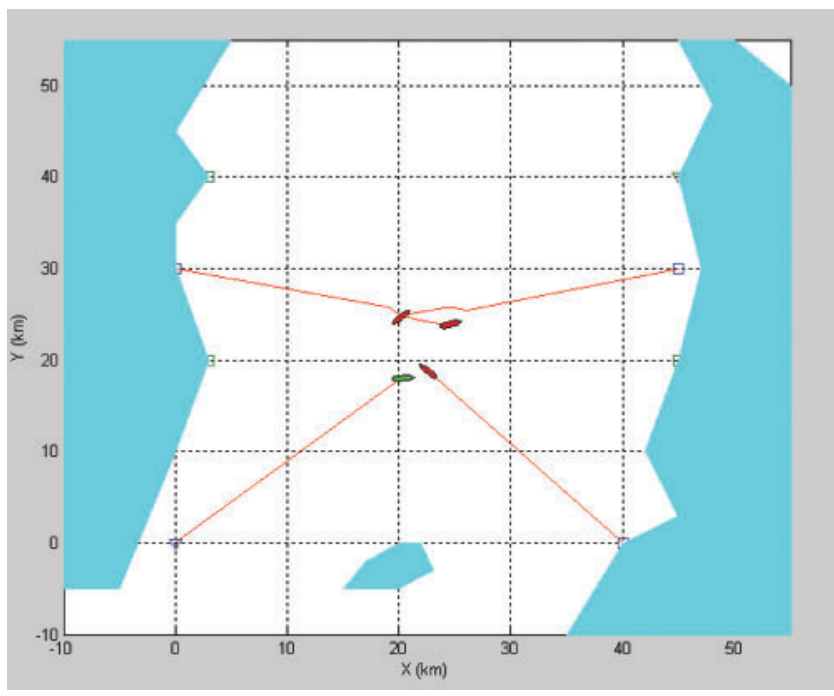

Fig. 17 Own ship manoeuvres

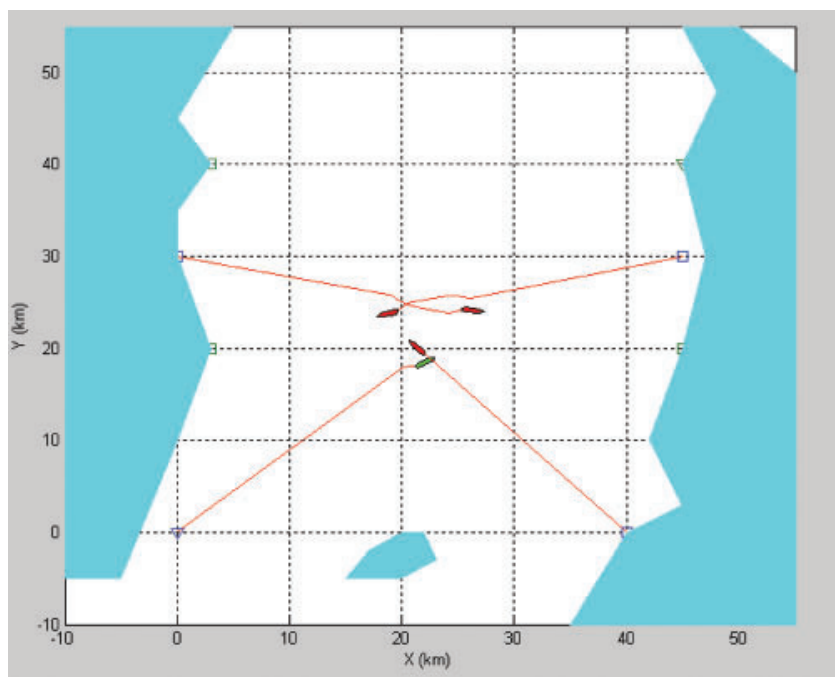

Fig. 18 All four ships complete the manoeuvre 


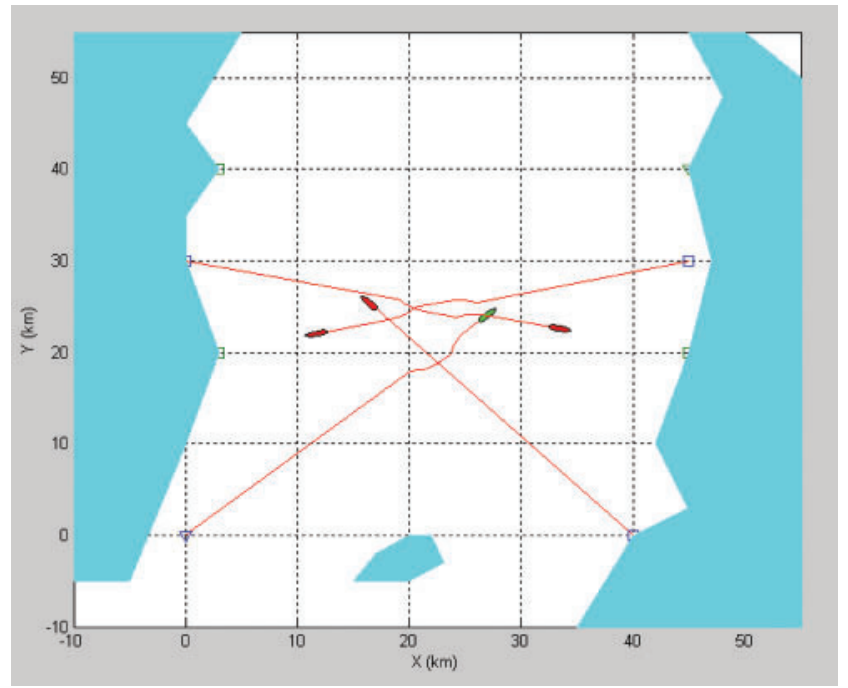

Fig. 19 Encounter resolved safely

Much work still remains to be done. For example, the extreme encounter cases where ordinary manoeuvres without emergency actions, such as change of speed or reverse action, may not be able to resolve the situation need to be studied. Furthermore, some rudiments of optimization of safe passages may be required to emulate the actions of human pilots. Nevertheless, it is thought that the current work has paved the way for designing an automatic manoeuvring simulator based on an artificial potential field method.

\section{REFERENCES}

1 Smith, C. Collision avoidance system and safe path generation, 4th year project, University of Strathclyde, 2008.

2 Shenhua Yang, Lina Li, Yongfeng Suo, and Guoquan Chen Study on construction of simulation platform for vessel automatic anti-collision and its test method. Proceedings of the IEEE International Conference on Automation and Logistics, Jinan, China, 2007.

3 Burnay, S., Manoeuvring simulation: a valuable aid to ship mooring and berthing, available from http://www.bmtseatech.co.uk.

4 Fossen, T. I. Guidance and control of ocean vehicles, 1994 (Wiley, Chichester).

5 Fossen, T. I. Marine control systems: guidance, navigation and control of ships, rigs and underwater vehicles, 1st edition, 2002 (Marine Cybernetics, Trondheim, Norway).

6 Ito, M., Feifei Zhang, and Yoshida, N. Collision avoidance control of ship with genetic algorithms. Proceedings of the 1999 IEEE International Conference on Control Applications, Kohala Coast, Hawaii, USA, August 1999, Vol. 2, pp. 1791-1796.
7 Zhao, J., Tan, M., Price, W. G., and Wilson, P. A. DCPA simulation model for automatic collision avoidance decision making system using fuzzy sets. Proceedings of OCEANS '94: Oceans Engineering for Today's Technology and Tomorrow's Preservation, Brest, France, September 1994, Vol. 2, pp. 244-249.

8 Saburo Tsuruta, Hisashi Matsumura, Masaaki Inaishi, Hayama Imazu, and Akio M. Sugisaki Basic research on an expert system for navigation at sea. Jap. Inst. Navigation, 1987, 77, 133-139.

9 Smierzchalski, R. and Michalewicz, Z. Modeling of ship trajectory in collision situations by an evolutionary algorithm. IEEE Trans. Evolutionary Computation, 2000, 4(3), 227-241.

10 Khatib, O. Real-time obstacle avoidance for manipulators and mobile robots. J. Robotics Res., 1986, 5(1), 90-98.

11 Crockcroft, A. N. and Lameijer, J. N. F. A guide to the collision avoidance rules, 5th edition, 1996 (BH Newnes, Oxford).

12 Hilgert, H. and Baldauf, M. A common risk model for the assessment of encounter situations on board ships. Ocean Dynamics, 1997, 49(4), 531-542.

13 Tran, T., Harris, C. J., and Wilson, P. A. A vessel management expert system. Proc. Instn Mech. Engrs, Part M: J. Engineering for the Maritime Environment, 2002, 216(2), 161-177. DOI: 10.1243/ 147509002762224379.

14 Storvik, M. Guidance system for automatic approach to a ship, Master's thesis, Department of Engineering Cybernetics, Norwegian University of Science and Technology (NTNU), Trondheim, 2003.

\section{APPENDIX}

\section{Notation}

$a, b$

ARPA

A

COLREGS international regulations for

$C_{\mathrm{A}}$

$C_{\mathrm{E}}$

$C_{\mathrm{R}}$

$C_{\mathrm{S}}$

$f$

F

$\boldsymbol{F}_{\text {att }}$

$\boldsymbol{F}_{\text {rep }}$

GA

$I_{Z} \quad$ yaw moment of inertia of the ship

$K_{\mathrm{p}}, K_{\mathrm{i}}, K_{\mathrm{d}}$

$L_{\mathrm{OW}}$ preventing collision at sea

angle

automatic radar plotting aids

matrix

avoidance collision distance

position evaluation error

distance of checking collision

safe passing distance

factor

total force

attractive force

repulsive force

genetic algorithm

controller gain constant

length of own ship 


\begin{tabular}{|c|c|c|c|}
\hline$L_{\mathrm{pp}}$ & $\begin{array}{l}\text { length of ship between perpendicu- } \\
\text { lars }\end{array}$ & $\begin{array}{l}\boldsymbol{U}_{\text {att }}(\boldsymbol{p}) \\
\boldsymbol{U}_{\text {rep }}(\boldsymbol{p})\end{array}$ & $\begin{array}{l}\text { attractive potential energy } \\
\text { repulsive potential energy }\end{array}$ \\
\hline$L_{\mathrm{TA}}$ & length of target ship & $\boldsymbol{U}(\boldsymbol{p})$ & gravity potential energy \\
\hline$m$ & positive constant & $V_{\mathrm{O}}$ & speed vector of own ship \\
\hline$m$ & mass of the ship & $\boldsymbol{V}_{\mathrm{OT}}$ & relative speed between own ship and \\
\hline$n$ & constant & & target ship \\
\hline$N$ & yaw moment & $\boldsymbol{V}_{\mathrm{T}}$ & speed vector of target ship \\
\hline$p$ & point on the water surface & $\left(x_{\mathrm{d}}(\theta), y_{\mathrm{d}}(\theta)\right)$ & position of the vessel \\
\hline $\begin{array}{l}\boldsymbol{p}_{\mathrm{d}} \\
\boldsymbol{p}(t)\end{array}$ & $\begin{array}{l}\text { destination position of ship } \\
\text { position of ship at time } t\end{array}$ & $X$ & $\begin{array}{l}\text { force applied on the ship in the } \\
x \text {-direction }\end{array}$ \\
\hline$p_{\mathrm{o}}$ & positive constant & $Y$ & force applied on the ship in the \\
\hline$p_{\mathrm{s}}$ & $\begin{array}{l}\text { distance between the ship and the } \\
\text { obstacle }\end{array}$ & & $y$-direction \\
\hline $\boldsymbol{P}_{\mathrm{O}}$ & position vector of own ship & $\alpha$ & scalar nositive narameter \\
\hline $\boldsymbol{P}_{\mathrm{T}}$ & position vector of target ship & $\alpha$ & \\
\hline $\boldsymbol{P}_{\mathrm{OT}}$ & $\begin{array}{l}\text { relative distance between own ship } \\
\text { and target ship }\end{array}$ & $\begin{array}{l}\eta \\
\theta\end{array}$ & $\begin{array}{l}\text { constant } \\
\text { variable }\end{array}$ \\
\hline$r, \dot{r}$ & yaw rate and yaw acceleration & $\xi$ & relative damping ratio \\
\hline$T_{\mathrm{d}}$ & derivative time constant & $\psi_{\mathrm{OS}}$ & course angle of own ship \\
\hline$T_{\mathrm{i}}$ & integral time constant & $\psi_{\mathrm{R}}$ & relative course angle \\
\hline$u, v$ & $\begin{array}{l}\text { surge speed and sway speed } \\
\text { respectively }\end{array}$ & $\begin{array}{l}\psi_{\mathrm{TS}} \\
\psi\end{array}$ & $\begin{array}{l}\text { course angle of target ship } \\
\text { heading error }\end{array}$ \\
\hline$\dot{u}, \dot{v}$ & $\begin{array}{l}\text { surge and sway acceleration } \\
\text { respectively }\end{array}$ & $\omega_{\mathrm{n}}$ & natural frequency \\
\hline
\end{tabular}

